\title{
Simultaneous Determination of Dopamine and Tyrosine Using Poly-glycine/Nafion/MWCNTs Functionalized Plastic-based Miniature Electrochemical Platform
}

\author{
Hui Yang ${ }^{*}$, Zhiqiang Wei, Ting Li, Liuyang Cheng, Yuanhui Li, Xue Zhang, Wenke Li, Yile Hu* \\ College of Medical, Henan University of Science and Technology, Luoyang, 471023, China. \\ *E-mail: yanghui7761@163.com, huyile2@163.com.
}

doi: $10.20964 / 2019.10 .18$

Received: 4 June 2019/ Accepted: 27 July 2019 / Published: 30 August 2019

In this study, a novel, simple, low cost and reproducible method is developed to fabricate plastic-based miniature electrochemical platform (PMEP), which integrated three electrodes including a polyglycine/Nafion/MWCNTs modified carbon paste electrode (p-Gly/Nafion/MWCNTs/CPE), a Pt wire counter electrode (CE) and an $\mathrm{Ag} / \mathrm{AgCl}$ wire reference electrode (RE). The pGly/Nafion/MWCNTs/CPE is prepared by drop-coating and in situ electrochemical polymeric deposition. The p-Gly/Nafion/MWCNTs functionalized PMEP (p-Gly/Nafion/MWCNTs/CPE-PMEP) demonstrates excellent electrocatalytic properties for the oxidation of dopamine (DA) and tyrosine (Tyr). Under the optimum conditions, the peak currents of DA and Tyr increase linearly with their concentrations in the ranges of $0.025-10 \mu \mathrm{M}$ DA and 0.2-40 $\mu \mathrm{M}$ Tyr. And the detection limits $(\mathrm{S} / \mathrm{N}=3)$ are $0.008 \mu \mathrm{M}$ and $0.07 \mu \mathrm{M}$, respectively. Furthermore, the proposed p-Gly/Nafion/MWCNTs/CPEPMEP is applied to simultaneous determination of DA and Tyr in human serum samples.

Keywords: Dopamine; Tyrosine; Plastic-based miniature electrochemical platform (PMEP); Polyglycine/Nafion/MWCNTs modified carbon paste electrode (p-Gly/Nafion/MWCNTs/CPE)

\section{FULL TEXT}

(C) 2019 The Authors. Published by ESG (www.electrochemsci.org). This article is an open access article distributed under the terms and conditions of the Creative Commons Attribution license (http://creativecommons.org/licenses/by/4.0/). 